\title{
PERMEABILITY ENHANCEMENT IN THE AQUIFER OF FUXIN WELL IN GEOTHERMAL AREA OF NORTHEASTERN CHINA INDUCED BY LOW-FREQUENCY TELESEISMIC WAVES OF THE $2011 M_{w} 9.0$ TOHOKU EARTHQUAKE
}

\author{
Yan ZHANG ${ }^{1)}$ *, Li-Yun FU ${ }^{1)}$, Fuqiong HUANG ${ }^{2)}$ and Xuezhong CHEN ${ }^{3)}$ \\ 1) Key Laboratory of the Earth's Deep Interior, Institute of Geology and Geophysics, Chinese Academy of Sciences, \\ No. 19, Beitucheng Western Road, Beijing 100029, China \\ 2) China Earthquake Networks Center, No. 5, Sanlihenanheng Avenue, Beijing100036, China \\ ${ }^{3)}$ Institute of Geophysics, China Earthquake Administration, No. 5 MinzuDaxue Nan Rd., Beijing 100081, China
}

*Corresponding author's e-mail: evezhangyan@mail.iggcas.ac.cn

\section{ARTICLE INFO \\ Article history: \\ Received 12 November 2014 \\ Accepted 6 February 2015 \\ Available online 23 February 2015 \\ Online corrected by authors 16 June 2015}

Keywords:

Permeability variation

Teleseismic waves

$M_{w} 9.0$ Tohoku earthquake

Coseismic water level changes

Volume strain variation

\begin{abstract}
The $M_{w} 9.0$ Tohoku large earthquake induces far field (epicentral distance $>1800 \mathrm{~km}$ ) prominent coseismic water-level increase in the Fuxin well at northeastern China, which also influences volumetric strains. Different mechanisms of far-field coseismic water-level changes are analyzed by integrating these water-level/volume-strain data with broadband seismograms from a nearby station. Dilatation induced by propagating teleseismic wave (central frequency $0.02 \mathrm{~Hz}$ ) may be the dominant mechanism of the observed water-level increases in the aquifer of Fuxin well. The dynamic energy density of $\sim 5 \times 10^{-2} \mathrm{~J} / \mathrm{m}^{3}$ from the earthquake (computed from broadband seismograms), could be large enough to incur the far-field dilatation stress of $\sim 0.35 \mathrm{MPa}$ (with the strain variation of $-3.7935 \times 10^{-6}$ ) in the aquifer. The resulting enhancement in permeability by the dilatation stress can build a new pore-pressure equilibrium between the Fuxin well and the nearby Sihe reservoir ( $\sim 150 \mathrm{~m}$ away from the Fuxin well). The induced interstitial fluid flow in the region accounts for the sustained large-amplitude coseismic water-level increase. The Fuxin well lies in the geothermal area, and this study may also has some implications for the geothermal resource exploration.
\end{abstract}

\section{INTRODUCTION}

It has been observed repeatedly that lowfrequency $(\sim 0.01 \mathrm{~Hz}-500 \mathrm{~Hz})$ seismic waves can enhance oil production from depleted reservoirs and contaminant extraction from groundwater aquifers. The physics of coupling stress waves to fluid flow behavior in the porous media is obscure, although numerous physical mechanisms have been proposed to explain those phenomena. To quantify the effects of low-frequency, dynamic-stress stimulation on fluid flow and the in-situ particle behavior in a porous media, precise measurement of earthquake induced stress, strain, and aquifer and fluid flow parameters are collected.

Large earthquakes often cause distinct changes of water levels, many occurred at great distances from the ruptured fault, with the static stress changes relatively small (e.g., Bower and Heaton, 1978; Matsumoto, 1992; Sil, 2006; Sil and Freymueller, 2006; Chadha et al., 2008). These changes correspond to rapid redistribution of pore pressure, which in turn initiates liquefaction (Wang, 2007) controls the timing and/or location of the aftershocks and trigger seismicity (e.g., Hill et al.,1993; Brodsky and Prejean, 2005; Manga and Brodsky, 2006), and causes transient crustal deformation (Johnston et al., 1995).

Some mechanisms are proposed for coseismic water-level changes, including pore-pressure increases caused by a mechanism 'akin to liquefaction' (Roeloffs, 1998), shaking-induced dilatancy (Bower and Heaton, 1978), coseismic growth of bubbles (Linde et al., 1994), and fracturing of an impermeable fault (King et al., 1999). Meanwhile, fracture clearing (unclogging) and permeability increasing, induced by earthquake dynamic stresses due to the propagation of teleseismic waves, have been widely used to explain most documented far-field water-level changes (e.g., Elkhoury et al., 2006; Wang and Manga, 2010). As indicated by Elkhoury et al. (2006), relatively small dynamic stresses can double or triple permeability and therefore suggests a possible method for active permeability enhancement in economically useful geothermal, natural gas and oil reservoirs. Overcoming the capillary entrapment in porous channels is hypothesized to be one of the principal pore-scale mechanisms by which natural permeability is enhanced by the passage of elastic waves (Beresnev et al., 2011).

The laboratory observation of fluid flow behavior in Berea sandstone induced by lowfrequency dynamic stress stimulation of Roberts (2005) indicates that during single-phase brine flow, stimulation increases the absolute permeability of the rock by $10-20 \%$. This is caused by mobilizing in situ clay particles that were partially plugging the pore throats. Laboratory experiments on the 


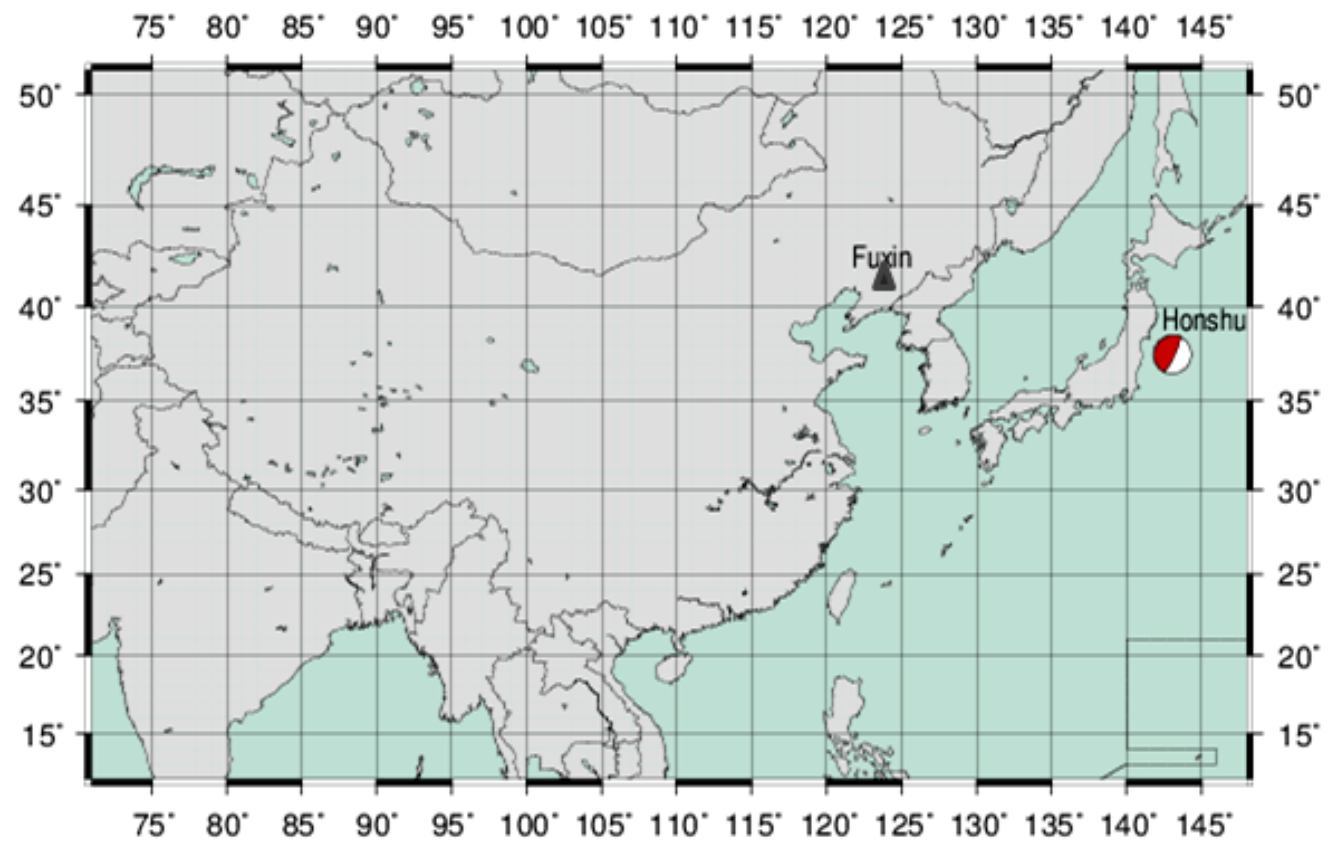

(a)

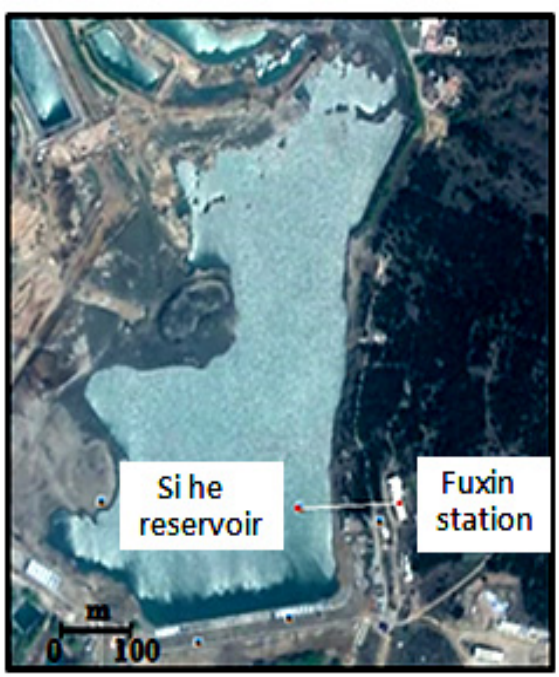

(b)

Fig. 1 Map showing the geographic position of the Fuxin well and the epicenter of the $2011 M_{w} 9.0$ Tohoku earthquake. (b) Local map (downloaded from Google Earth) showing the relative positions of the Fuxin well and the Sihe reservoir, with about $150 \mathrm{~m}$ between them.

fractured rock by Elkhoury et al. (2011) find that the maximum value of effective permeability enhancement is $5 \times 10^{-16} \mathrm{~m}^{2}$ and the maximum enhanced permeability is $1.5 \times 10^{-15} \mathrm{~m}^{2}$. There work suggests the feasibility of dynamically controlling the effective permeability of fractured systems. Manga et al. (2012) studied the mechanism of permeability change with field observations and experiments. As they concluded, in natural systems, strain amplitudes as small as $10^{-6}$ can enhance permeability, the mechanisms include unblocking pores, either by breaking up permeability-limiting colloidal deposits or by mobilizing droplets and bubbles trapped in pores by capillary forces. Recent laboratory studies by Candela et al. (2014) show that both the direct enhancement of permeability and its recovery can be explained by the fast flushing and gradual re-clogging of fines at pore throats or between fracture asperities.

Yan et al. (2014) studied groundwater-level changes induced by the $2011 M_{w} 9.0$ Tohoku earthquake in the Chinese mainland; they found that earthquake-induced temporal variations in permeability could have occurred at about $43 \%$ of the wells that displayed sustained water level changes, but at 
less than $15 \%$ of all the observed wells. In addition, they found that the permeability even decreased in some wells, and their statistical analysis did not indicate any obvious significant relationships between water-level changes and any other parameter (except the tidal admittance), indicating that the processes behind groundwater level changes induced by a distant great earthquake are complex.

Based on the observation of both water levels and volume strains in the Fuxin well, northeastern China, the $2011 M_{w} 9.0$ Tohoku earthquake produced huge-energy teleseismic waves, leading to an extreme decrease of volume strain and an abrupt increase of water level in the aquifer at far fields (epicentral distance $>1800 \mathrm{~km}$ ). Here, we examine such largeamplitude coseismic changes that may be associated with some distinct mechanisms. Since different mechanisms require different amounts of dynamic energy to activate, we calculate the dynamic energy density in the region using broadband seismograms from a nearby SNY station (the distance between them is about $102.81 \mathrm{~km})$. Referring to Wang and Chia (2008) and Manga et al. (2012), we correlate the dynamic energy and the strain variation with the observed data in the Fuxin well to discriminate among the mechanisms for the large-amplitude coseismic changes. The results suggest that teleseismic waves with a dynamic energy density of $\sim 5 \times 10^{-2} \mathrm{~J} / \mathrm{m}^{3}$ could be strong enough to activate far-field dilatation with $\sim 0.35 \mathrm{MPa}$ (the induced coseismic strain variation is $\left.-3.7935 \times 10^{-6}\right)$ in the aquifer. Such a dilatation can enhance the permeability significantly, leading to pore-pressure equilibrium between the Fuxin well and the nearby Sihe reservoir ( $150 \mathrm{~m}$ away from the Fuxin well). The resulting interstitial fluid flow in the region is responsible for the sustained large-amplitude coseismic water-level increase in the Fuxin well.

\section{OBSERVATIONS}

The Fuxin well (Figure 1a) is located in the Fuxin city of Liaoning province in northeastern China and in the northwest of the Fuxin Graben Basin. The region near the well lies at a tectonic cross-section between the Yinshan and Neocathaysian structural belts. The depth of the Fuxin well is $60.74 \mathrm{~m}$. The stratigraphy at the well is as follows: $0-15 \mathrm{~m}$ is a relatively unconsolidated formation, $0-1.5 \mathrm{~m}$ is Quaternary stratum, and $1.5-15 \mathrm{~m}$ is formed by Cretaceous gravels, tuff, and andesite. 15-60.74 m consists of the Liao River System monzonitic granite. Figure 2 shows the lithologic log of the Fuxin well.

The TJ-2 type drilled strain gauge is installed at the bottom of the well to measure volume strains, with its observational sensitivity $\geq 2.0 \mathrm{mV} / 10^{-8}$, resolution ratio $\leq 1 \times 10^{-9}$, and noise level $<0.1 \mathrm{mV}$. It has been working since April 1st, 2001 and can record the Earth tides clearly and stably. Moreover, as a supplementary to volume strain, there are other downhole instruments to measure water levels and atmospheric pressures, with sensitive parameters of

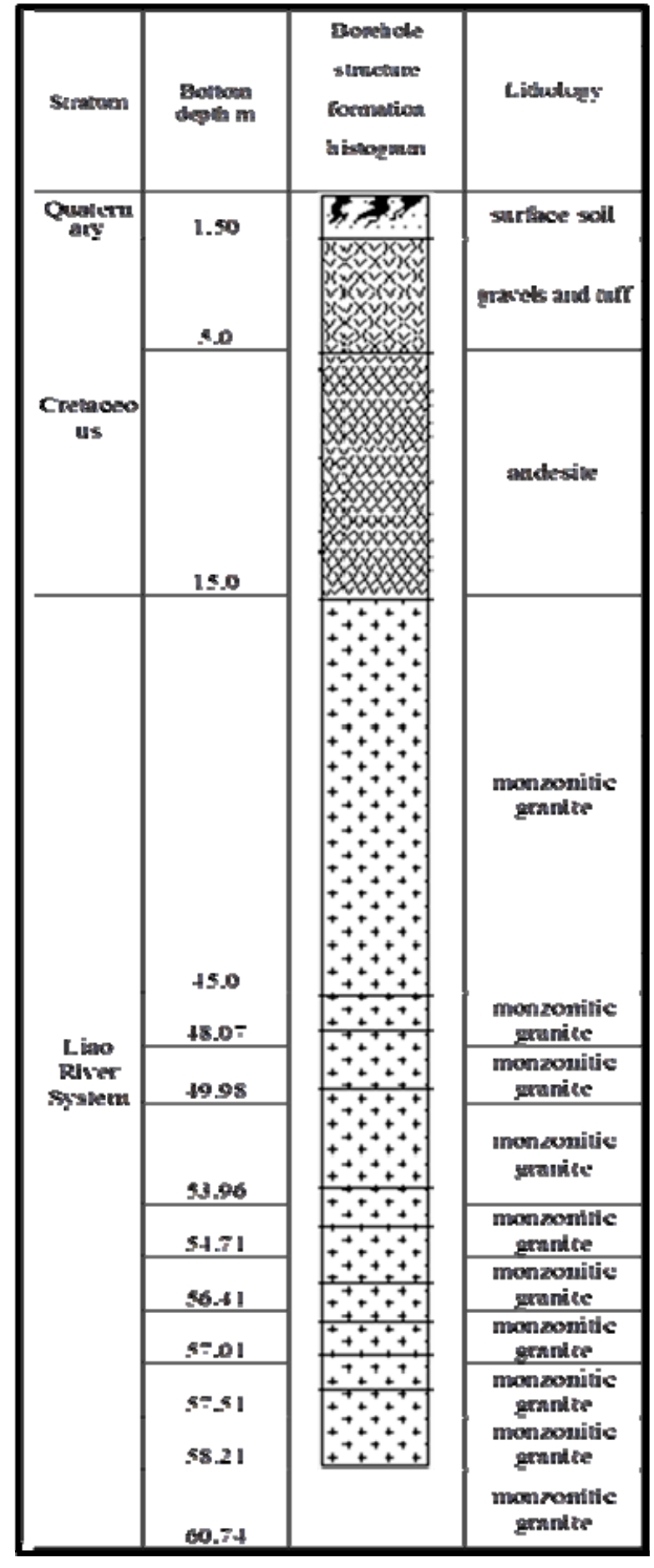

Fig. 2 Lithologic $\log$ of the Fuxin well from $<$ Seismic monitoring records of China $>$.

$1 \mathrm{~cm} / \mathrm{mV}$ for the SQ digital water-level instrument and $1 \mathrm{hPa} / \mathrm{mV}$ for the SQ digital atmospheric-pressure instrument. The water-level instrument has been set to record data in every minute since 2009 .

As an artesian well with the aquifer confined, the water-level measurements are directly related to the changes in pore pressure. Based on the datasets, we use the Mapsis software (Lu et al., 2002) to calculate the theoretical Earth tides (tidal volumetric strains). 
Fig. 1 Comparison of the coseismic water-level and volume-strain changes at the Fuxin well induced by the $2011 M_{w} 9.0$ Tohoku earthquake. The background volume-strain variability for each earthquake is computed as a standard deviation of the continuously observed data during the 2.5 months before the earthquake. The negative coseismic volume strain change indicates a decrease of lithological complexes volume, i.e. in fact its consolidation.

\begin{tabular}{|c|c|c|c|c|c|c|c|c|}
\hline Epicenter & Magnitude & $\begin{array}{l}\text { Occurrence } \\
\text { time } \\
\text { (Beijing) }\end{array}$ & $\begin{array}{l}\text { Epicentral } \\
\text { distance } \\
\text { change } \\
(\mathrm{km}) \\
\end{array}$ & $\begin{array}{c}\text { Coseismic } \\
\text { water level } \\
\text { change } \\
(\mathrm{cm}) \\
\end{array}$ & $\begin{array}{l}\text { Background } \\
\text { volume } \\
\text { strain } \\
\text { variability } \\
\left(10^{-9}\right) \\
\end{array}$ & $\begin{array}{l}\text { Coseismic } \\
\text { volume strain } \\
\text { change } \\
\left(10^{-9}\right)\end{array}$ & $\begin{array}{l}\text { Coseismic } \\
\text { stress } \\
\text { change } \\
(\mathrm{MPa}) \\
\end{array}$ & $\begin{array}{c}\text { Static } \\
\text { volume } \\
\text { strain } \\
\text { change } \\
\left(10^{-9}\right) \\
\end{array}$ \\
\hline $\begin{array}{l}\text { Near the } \\
\text { east coast } \\
\text { of Honshu, } \\
\text { Japan }\end{array}$ & $M_{w} 9.0 / M_{S} 8.7$ & $\begin{array}{l}13: 46: 19.0 \\
11 \text { March } 2011\end{array}$ & 1828.55 & 42.2 & 45.87 & -3793.5 & -0.341415 & -10 \\
\hline
\end{tabular}
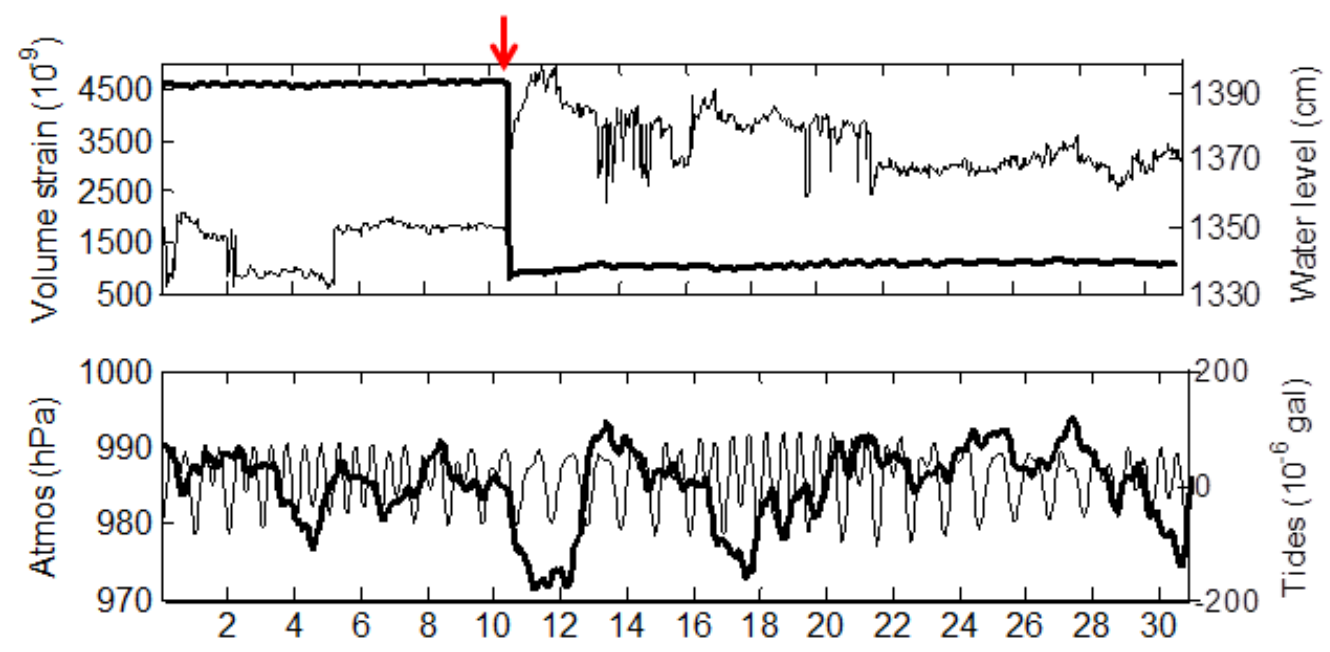

$M_{w} 9.0$ Tohoku earthquake (Mar. 1-31, 2011)

Fig. 3 Original water-level (thin line), volume-strain (thick line), Earth-tides (thin line), and atmosphericpressure (thick line) variations versus time for the Fuxin well before and after the $2011 M_{w} 9.0$ Tohoku earthquake. The arrow indicates the occurrence time of the earthquake. The original water level changes before the earthquake indicate that the aquifer in the Fuxin well may be semi-confined.

Table 1 lists some basic earthquake parameters, coseismic water-level/volume-strain datasets, and background (pre-earthquake) volume-strain variability. Figure 3 compares original water-level, volume-strain, Earth-tides, and atmospheric-pressure variations observed from the Fuxin well before and after the earthquake. We see that both the water-level and volume-strain changes show obvious coseismic responses to the Tohoku earthquake at far fields.

The original water-level and volume-strain variations versus time for the Fuxin well before and after the earthquake were corrected by detrending and removing the influence of tidal strain (removing the major tidal constituents, $2 \mathrm{Q}_{1}, \mathrm{Q}_{1}, \mathrm{O}_{1}, \mathrm{M}_{1}, \mathrm{P}_{1}, \mathrm{~S}_{1}, \mathrm{~K}_{1}$, $\mathrm{J}_{1}, \mathrm{OO}_{1}, 2 \mathrm{~N}_{2}, \mathrm{~N}_{2}, \mathrm{M}_{2}, \mathrm{~L}_{2}, \mathrm{~S}_{2}, \mathrm{~K}_{2}, \mathrm{M}_{3}$, by filtering based on the Fourier transform) and atmospheric pressure (we decomposed the barometric fluctuation into several temporal series in different frequency ranges; the barometric coefficient in different frequency ranges was computed with the least squares method to remove the barometric response in the water level and volume strain; this is similar to the method of Yan et al (2006)); the result is shown in Figure 4. It can be seen that the relationship between them becomes more obvious as compared to Figure 3.

\section{WATER-LEVEL STEPS}

Based on the lithologic log shown in Figure 2, hydraulic parameters were estimated by referring to Wang (2000) for the typical values of different lithologies. The resulting values used in this study were: hydraulic conductivity $K=10^{-9} \mathrm{~ms}^{-1}$, specific storage $S_{s}=10^{-7} \mathrm{~m}^{-1}$, and permeability $k=10^{-16} \mathrm{~m}^{2}$. The hydraulic diffusivity of the aquifer at the Fuxin well was calculated using $D=K / S_{s}=10^{-2} \mathrm{~m}^{2} / \mathrm{s}$. As is well known, the duration of water-level drops/rises is strongly related to the distance from a well to the localized source of pore-pressure changes (Roeloffs, 1998). As shown by Brodsky et al. (2003), for time periods with durations much greater than that of the corresponding seismic wave train, the pressure-step effect on the well can be modeled as a one- 


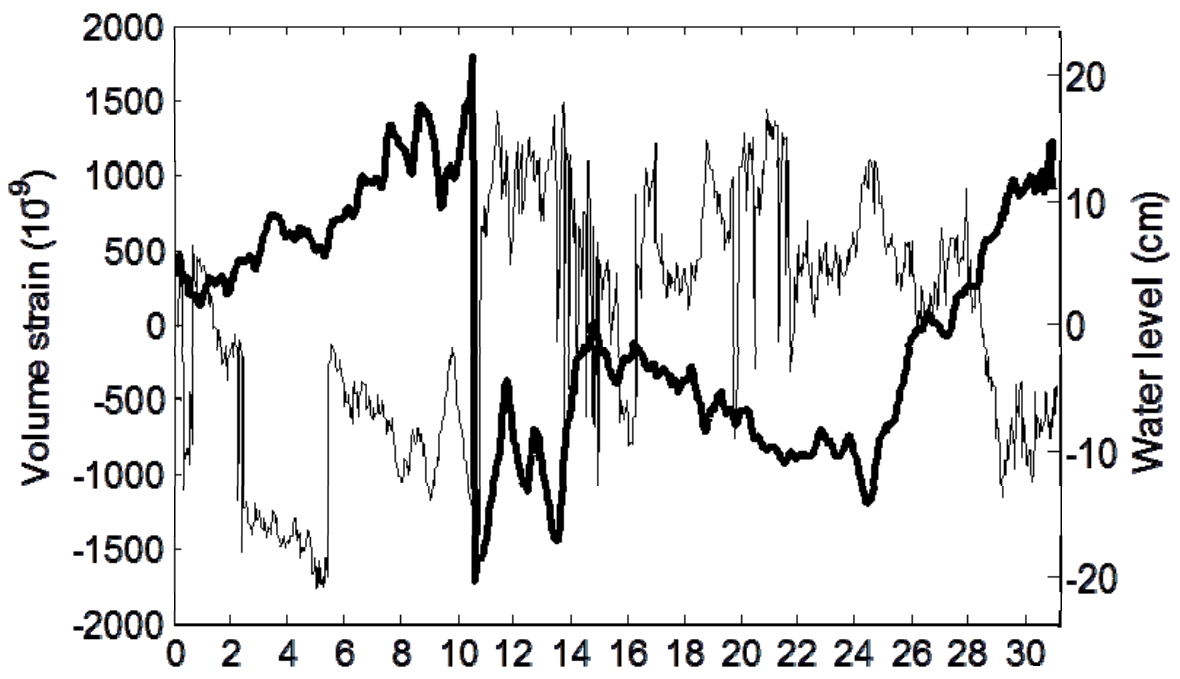

$M_{w} 9.0$ Tohoku earthquake (Mar. 1-31, 2011)

Fig. 4 Corrected water-level (thin line) and volume-strain (thick line) variations versus time for the Fuxin well before and after the $2011 M_{w} 9.0$ Tohoku earthquake.

dimensional solution to a diffusion equation in an unbounded, homogeneous aquifer (Crank, 1975). The pattern of the step-like coseismic water level change induced by the Tohoku earthquake is formed by three parts. In order to obtain the best model, we used the equation of Sil (2006) to fit the water level time series with a combination of a linear trend (for pre-seismic), a step function (for coseismic), and an error function (for post-seismic):

$$
w(t)=I+S t+C H\left(t-t_{0}\right)+\frac{\Delta p}{\rho g} \operatorname{erfc}\left(d / \sqrt{4 D\left(t-t_{0}\right)}\right)
$$

where $I$ (intercept) and $S$ (slope) are constants that describe the linear pre-earthquake trend, $C$ is a constant (magnitude of the step), $\mathrm{H}$ is the Heaviside (step) function, erfc is the complementary error function, $\Delta p$ denotes the pressure-drop amplitude at the source, $d$ indicates the distance from the source to the well, $\mathrm{g}$ is the acceleration due to gravity, and $\rho$ is the density of water. The time of the earthquake is $t_{0}=0$ and $\mathrm{w}(\mathrm{t})$ is the observed water level at any time $t$ of our time series.

As shown in Figure 5, the least squares fit with equation (1) for the water-level record yields

$$
\begin{gathered}
w(t)=1350.5-0.0052 t+20 H\left(t-t_{0}\right)+ \\
+51 \operatorname{erfc}\left(3679.13 / \sqrt{4 \times 100 \times\left(t-t_{0}\right)}\right)
\end{gathered},
$$

and we obtain $d=36.791 \mathrm{~m}$. Since the source-towell distance is less than $150 \mathrm{~m}$, the coseismic waterlevel increase may be associated with the Sihe reservoir that is $150 \mathrm{~m}$ from the Fuxin well. The Sihe reservoir is a small size reservoir, and lies to the northwest of the Fuxin well. After repeated surveys, the earthquake administration of Liaoning province showed that the Sihe reservoir has no influence on the water quality, water level, or volumetric strain of the Fuxin well under normal circumstances $(<$ Seismic monitoring records of China $>$ ).

\section{PERMEABILITY CALCULATION}

Periodical changes in Earth tides cause well aquifers to expand or contract, resulting in fluctuations of pore fluid pressure, further leading to corresponding fluctuations of the water-level in wellbores that are connected to confined aquifers (Hsieh et al., 1987). The most commonly analyzed phase is $\mathrm{M}_{2}$ because of its large amplitude and relatively low contamination by barometric pressure or diurnal temperature fluctuations (Hsieh et al., 1987; Rojstaczer and Agnew, 1989; Doan et al., 2006). In this work, we also focused on the $\mathrm{M}_{2}$ phase (period $745.2 \mathrm{~min}$ ). We calculated the phase lag between the water level and the Earth tides based on the crosscorrelation method, with a moving time window of 30 days and a running step of 3 days (Figure 6).

According to Hsieh et al. (1987), for a homogeneous, isotropic, laterally extensive, and confined aquifer, the phase shifts between earth tides and water level are assumed to be caused by the time required for water flowing into and out of the well. In such a case, the water-table drainage effect is ignored and the resulting phase shift should always be negative. In other words, the phase-shift increase (e.g., from $-5^{\circ}$ to $-1^{\circ}$ ) implies an increase in transmissivity or permeability (Hsieh et al., 1987; Elkhoury et al., 2006). Based on our datasets, however, positive phase shifts are commonly observed, as shown in Figure 6, indicating that Hsieh's model does not describe all the water-level responses to Earth tides. Roeloffs (1996) 


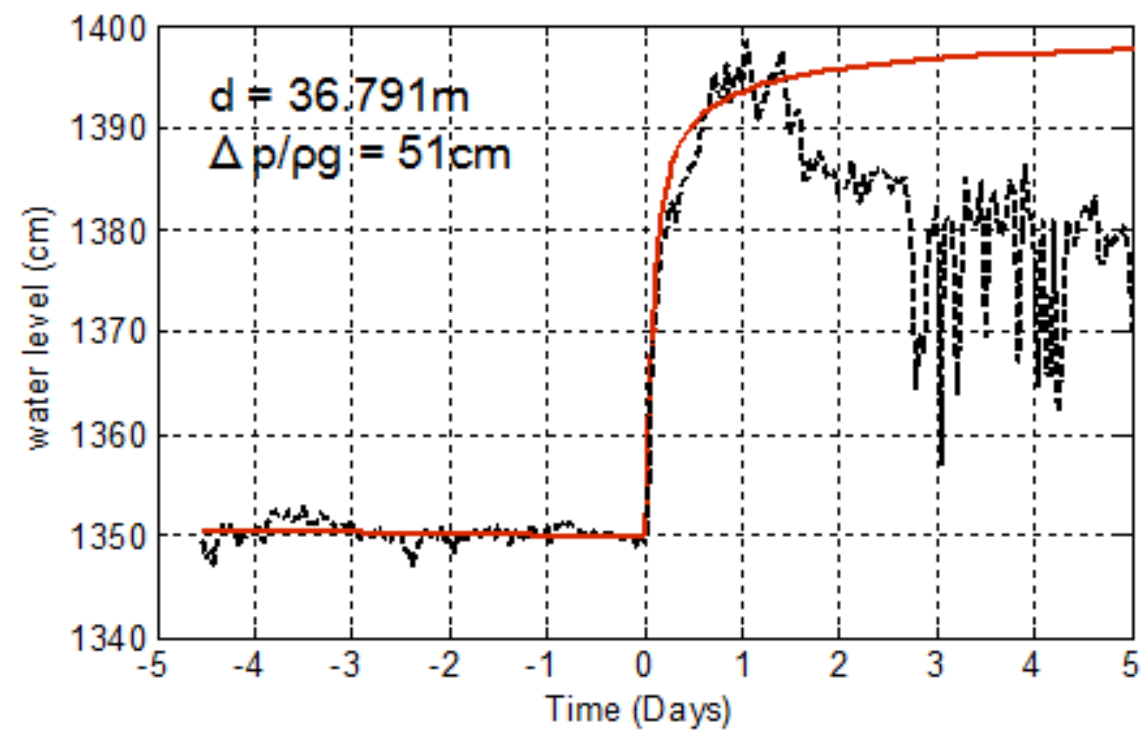

Fig. 5 A least squares fit with equation (1) for water-level records before and after the Tohoku earthquake. The data (dashed lines) show the original water level during the Tohoku earthquake (time 0). The smooth curve is a least squares fit of equation (1) to the data for the time of $-4.5 \sim 1.5$ days with $\mathrm{D}=100 \mathrm{~cm}^{2} / \mathrm{s}$.
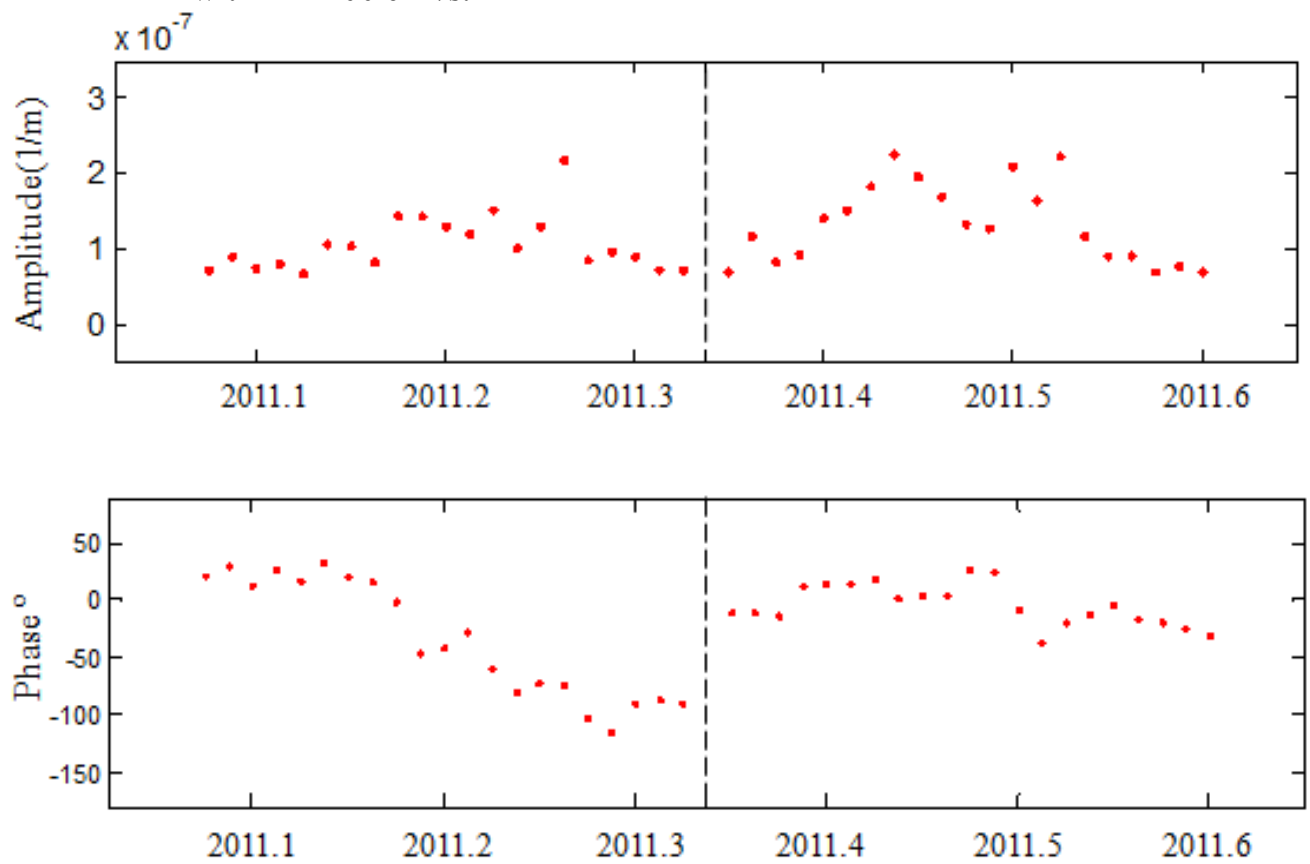

Fig. 6 Amplitude and phase responses over time for the Fuxin well at the frequency of the $\mathrm{M}_{2}$ wave. The amplitude response is the amplitude ratio of earth tides over water level. The dotted lines show the start time of the $M_{\mathrm{w}} 9.0$ Honshu earthquake on March 11, 2011 at 13:46 (Beijing time). The phase shift increased obviously after the earthquake, while the amplitude response remained unchanged.

presented a model in which vertical drainage of the water table could cause positive phase shifts. Figure 6 shows that phase responses at the Fuxin well varied between positive and negative values over time. The phase shifts are a combination of the phase lag due to borehole storage effects and the phase lead due to water-table drainage. As shown by Lai et al. (2013) for both the models of horizontal fluid flow (Hsieh et al., 1987) and vertical pore-pressure diffusion (Roeloffs, 1996), the observed phase responses can be considered as a measure of permeability, i.e., the phase-shift increase (e.g., from $-10^{\circ}$ to $-5^{\circ},-5^{\circ}$ to $5^{\circ}$, or $5^{\circ}$ to $10^{\circ}$ ) implies a permeability increase. As indicated in Figure 6 and Table 2, the phase shift 
Table 2 The coseismic phase and amplitude response at the Fuxin well. The reported initial phase and amplitude are the average value of the points within 30 days before the earthquake. The background phase and amplitude variability are the standard deviation of the phases and amplitudes before the earthquake for each well. The reported phase and amplitude change were obtained by the average value of the points within 30 days after the earthquake minus the initial phase and amplitude.

\begin{tabular}{ccccccc}
\hline $\begin{array}{c}\text { Initial } \\
\text { phase }^{\circ}\end{array}$ & $\begin{array}{c}\text { Background } \\
\text { phase }^{\text {variability }}{ }^{\circ}\end{array}$ & $\begin{array}{c}\text { Coseismic } \\
\text { phase } \\
\text { change }^{\circ}\end{array}$ & $\begin{array}{c}\text { Initial } \\
\text { amplitude/ } \\
\times 10^{-6} 1 / \mathrm{m}\end{array}$ & $\begin{array}{c}\text { Background } \\
\text { amplitude } \\
\text { variability } / \times 10^{-6} \\
1 / \mathrm{m}\end{array}$ & $\begin{array}{c}\text { Coseismic } \\
\text { amplitude } \\
\text { change } / \times 10^{-6} 1 / \mathrm{m}\end{array}$ & mm/nanostrain \\
\hline-88.4058 & 50.009 & 91.3647 & 0.109 & 0.0361 & 0.0255 & 4.5474 \\
\hline
\end{tabular}

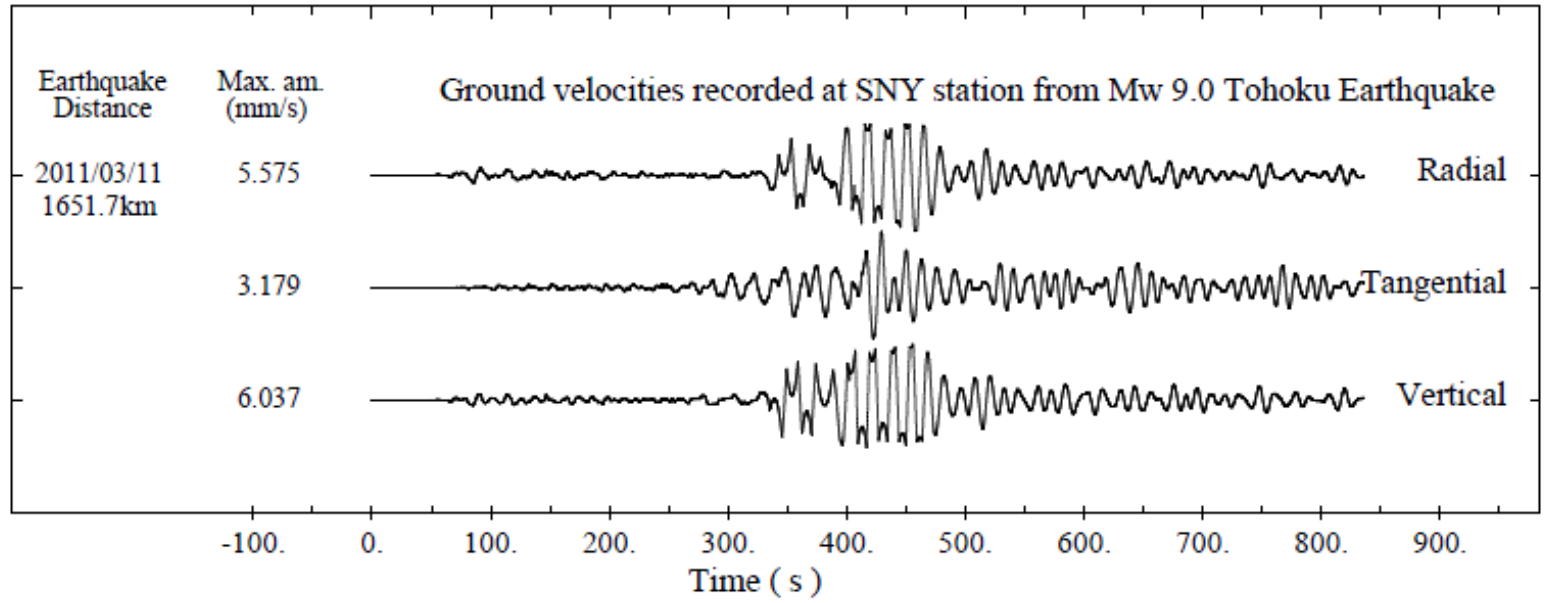

Fig. 7 Seismograms at the SNY station for the $2011 M_{w} 9.0$ Tohoku earthquake.

increases after the Honshu earthquake represents a permeability increase. The Fuxin well shows large amplitude responses to tides $(4.5474 \mathrm{~mm}$ per nanostrain (Table 2)); thus, the tidal signal is wellseparated from the noise level.

\section{SEISMOGRAMS, PGV, AND ENERGY DENSITY}

As indicated by Brodsky et al. (2003), only sufficient induced flow velocity can result in unclogging. However, we lack the observation of induced flow velocities, or the high-sampling records of water levels from which the flow velocity can be deduced (Wang et al., 2009). The water-level records available to us are sampled at hour or minute frequencies and are not precise enough for this purpose. We have to resort to the analysis of energy density (Wang and Chia, 2008). Using a plotting software (Zhao et al., 2008), we prepared the seismograms at the SNY station (the central frequency of the teleseismic waves received by SNY station is $0.02 \mathrm{~Hz}$ ), as shown in Figure 7, which were used to extract certain information correlated with the coseismic response in the Fuxin well. The distance between them is about $102.81 \mathrm{~km}$, short enough for both sites to experience similar effects from the teleseismic waves. In addition, the geology at both sites are similar, with their main matrix rocks consisting of granites.
With the seismograms shown in Figure 7, the first key parameter, the peak ground velocity (PGV) of the z-component, was calculated as $6.037 \mathrm{~mm} / \mathrm{s}$. Therefore, the z-component energy density was calculated using

$$
\begin{aligned}
e=\frac{A}{V}= & \frac{1 / 2 m v_{z}{ }^{2}}{V}=\frac{1 / 2\left(\rho_{s} V\right) v_{z}{ }^{2}}{V}= \\
& =1 / 2 \rho_{s} v_{z}^{2}=4.829 \times 10^{-2} \mathrm{~J} / \mathrm{m}^{3}
\end{aligned},
$$

where $A$ is the seismic energy, $m$ the mass, $V$ the volume, $v_{z}$ the z-component velocity, and the density of the rock matrix in the well aquifer $\rho_{s}=2.65\left(\mathrm{~g} / \mathrm{cm}^{3}\right)$. Because of the short distance between the Fuxin well and the SNY station, the energy density $\left(4.829 \times 10^{-2} \mathrm{~J} / \mathrm{m}^{3}\right)$ could be taken as the regional value resulting from the far-field effect of the Tohoku earthquake. Based on the statistics of a global dataset from southern California, Wang and Chia (2008) showed that there were sustained water-level changes resulting from the earthquake-enhanced permeability caused by energy densities between $10^{-4} \mathrm{~J} / \mathrm{m}^{3}-10^{-1} \mathrm{~J} / \mathrm{m}^{3}$ in the far field $(>1000 \mathrm{~km})$. Below the threshold value, the flow velocity induced by this energy may not be large enough to cause unclogging in an aquifer. Hence the energy density $\left(4.829 \times 10^{-2} \mathrm{~J} / \mathrm{m}^{3}\right)$ in northeastern 


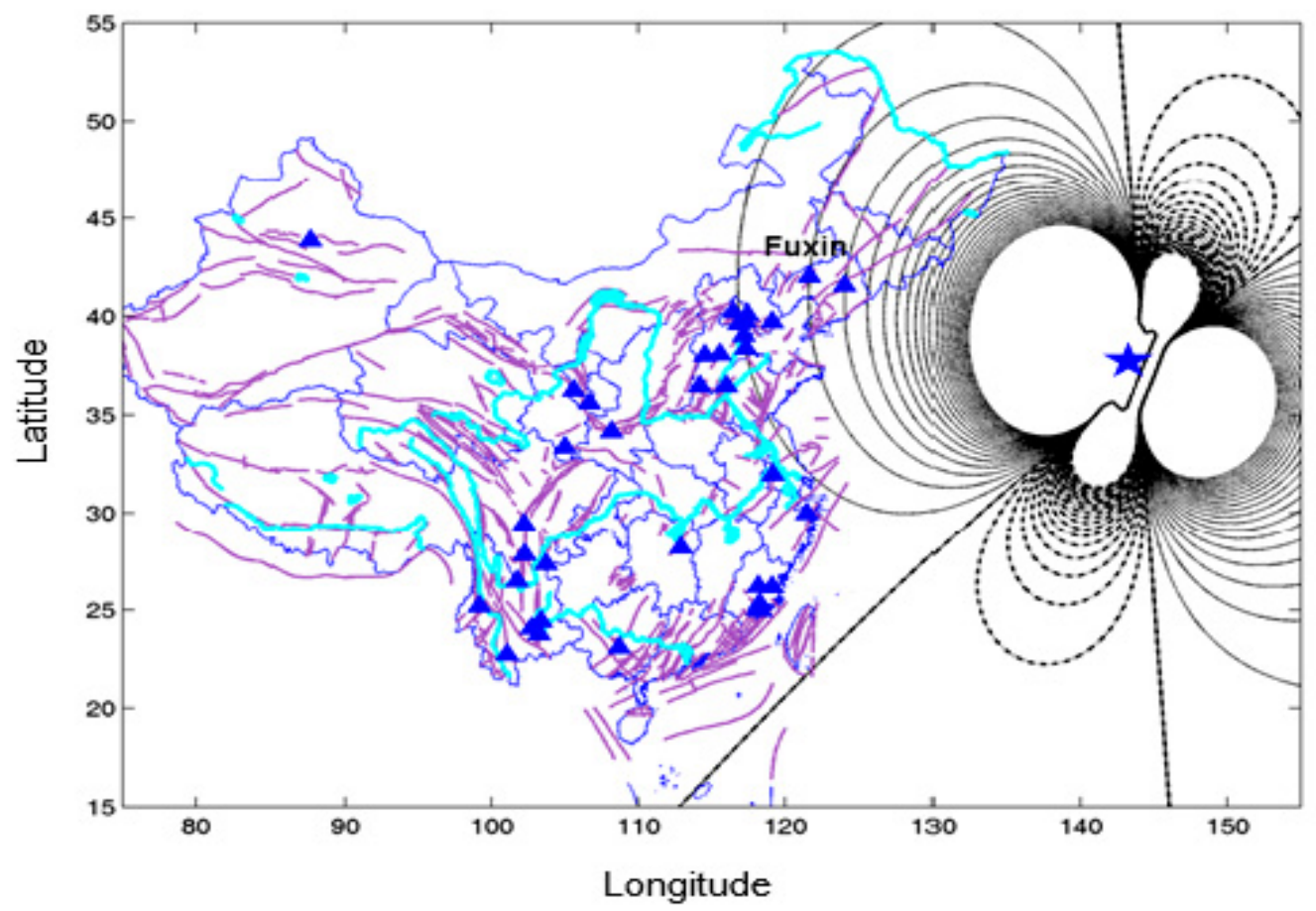

Fig. 8 The spatial distribution of the static volume strain change of the Tohoku earthquake calculated according to an elastic half-space dislocation model (Okada, 1992; Lin and Stein, 2004; Toda et al., 2005). The curved solid lines indicate inflation, while the curved dashed lines represent compression. The star is the epicenter of the earthquake, the triangles represent the distributed observation stations, the purple lines are the faults, and the bright clear blue lines indicate rivers. Parameters of the focal mechanism (Harvard Global CMT): trend, 203 ${ }^{\circ}$; angle of inclination, $10^{\circ}$; angle of slide, $88^{\circ}$; depth, $20 \mathrm{~km}$; rupture length, $450 \mathrm{~km}$; width, $150 \mathrm{~km}$; and slide range, $2500 \mathrm{~cm}$ (reference: http://www.jma.go.jp /jma/en/2011_Earthquake/chart/2011_Earthquake_ Source Process.pdf).

China induced by the shaking of the 2011 Tohoku earthquake could have enhanced the permeability resulting in a sustained water-level increase in the farfield.

\section{MECHANISM ANALYSIS}

As shown in Figure 3, the decrease of coseismic stresses to $\sim 0.35 \mathrm{MPa}$ in the aquifer of the Fuxin well induces an abrupt increase of water levels to $42.2 \mathrm{~cm}$. To explain the phenomenon more clearly, the staticstrain change in this well is required. Based on the elastic half-space dislocation model (Okada, 1992; Lin and Stein, 2004; Toda et al., 2005), we calculated the coseismic static-strain change in the Fuxin well, the result of which is shown in Figure 8 and Table 1; it can be seen that the static volume strain changes slightly during the earthquake (much smaller than that of the coseismic volume strain), i.e., the coseismic volume-strain variation is largely induced by the dynamic stresses. According to the general range of elastic moduli for some typical rocks (Liu and Tang, 1998), we set the dynamic elastic modulus $E=90 \mathrm{GPa}$ for the bedrock (stiff granites) in the Fuxin well. With the observed volume-strain change
( $\Delta \varepsilon_{k k}$ ), we computed the coseismic stress change $\Delta \sigma_{k k}=E \Delta \varepsilon_{k k}=0.34142 \mathrm{MPa}$. As indicated by King et al. (1999), fracture of an impermeable fault can be induced in the far field. According to Chen and Huang (2001), the laboratory-derived failure limit for typical granites ranges from 4-7 $\mathrm{MPa}$. Therefore, the resulting coseismic stress change $(0.34142 \mathrm{MPa})$ induced by the $2011 M_{w} 9.0$ Tohoku earthquake was not large enough to cause failures or damage to zones in the aquifer. As calculated above, the energy density $\left(4.829 \times 10^{-2} \mathrm{~J} / \mathrm{m}^{3}\right)$ of the teleseismic waves was sufficient to enhance the permeability for a sustained water-level increase in the far field. In addition, as shown by Manga et al. (2012), in natural systems, strain amplitudes as small as $10^{-6}$ can enhance permeability. The strain amplitude induced by the Tohoku earthquake was $-3.7935 \times 10^{-6}$; thus, it could have increased the permeability. In conclusion, shaking by teleseismic waves can induce far-field dilatation in an aquifer, leading to permeability enhancement.

Because of the slow decrease of post-earthquake water levels with irregular fluctuations, the aquifer 
should be in a drained condition after the earthquake. Since pore-pressure heterogeneity may be the norm in the field, an enhancement of permeability among sites with different pore pressures will cause the pore pressure to spread (Roeloffs, 1998; Brodsky et al., 2003; Wang, 2007; Wang and Manga, 2010). Water flowed into the well aquifer from the nearby Sihe reservoir ( $\sim 150 \mathrm{~m}$ away from the Fuxin well) to equilibrate the pore pressure differences. In other words, the resulting permeability enhancement could have created a new pore-pressure equilibrium between the Fuxin well and the nearby Sihe reservoir. The induced interstitial fluid flow in the region was responsible for the sustained large-amplitude coseismic water-level increase.

\section{CONCLUSIONS}

A detailed mechanism of coseismic water level change induced by a huge earthquake $\left(>M_{w} 9.0\right)$ was presented in this paper. We show that shaking induced by the transmission of teleseismic waves can cause dilatation in a well aquifer, which can enhance the permeability. This enhanced permeability may have connected the Fuxin well to a nearby pressure source (Sihe reservoir); the resulting pore-pressure equilibrium between the Fuxin well and the nearby Sihe reservoir leads to interstitial fluid flow in the region, thus increasing the coseismic water levels. Furthermore, the enhanced permeability occurred upgradient, causing the positive change of water level in the Fuxin well. This study also indicates that an energy density of $\sim 5 \times 10^{-2} \mathrm{~J} / \mathrm{m}^{3}$ is sufficient to cause dilatation with $\sim 0.35 \mathrm{MPa}$ (the induced coseismic strain decrease $\sim 3.8 \times 10^{-6}$ ) in an aquifer in the far field. Because the Fuxin well lies in a geothermal area (Wang and $\mathrm{Xu}, 2011$ ), the relationship between the energy density induced by the dynamic shaking and the resulting variation of coseismic stress may have some implications for drilling for geothermal resources. Further understanding of these phenomena will be facilitated by simultaneous measurements of discharge, temperature, water level, and chemical parameters at the Sihe reservoir (Figure1-(b)), which need to be performed in the future.

\section{DATA AND RESOURCES}

Data used in this paper were collected using a classified network (Groundwater Monitoring Network, GMN) of the China Earthquake Networks Center and cannot be released to the public. We use the Mapsis software (Lu et al., 2002) to calculate the Earth tides.

\section{ACKNOWLEDGEMENTS}

The authors gratefully acknowledge Samik Sil for his help, and sincerely thank Lianfeng Zhao, Yongge Wan, Yuchuan Ma, and Bo Zhao for their helps and valuable suggestions. This research was supported by the Strategic Leading Science and
Technology Programme (Class B) of the Chinese Academy of Sciences (Grant No. XDB10010400).

\section{REFERENCES}

Beresnev, I., Gaul, W. and Vigil, R.D.: 2011, Direct porelevel observation of permeability increase in twophase flow by shaking. Geophys. Res. Lett., 38, L20302. DOI: 10.1029/2011GL048840

Bower, D.R. and Heaton, K.C.: 1978, Response of an aquifer near Ottawa to tidal forcing and the Alaskan earthquake of 1964. Can. J. Earth Sci., 15, 331-340. DOI: $10.1139 / \mathrm{e} 78-039$

Brodsky, E.E., Roeloffs, E., Woodcock, D., Gall, I. and Manga, M.: 2003, A mechanism for sustained groundwater pressure changes induced by distant earthquake. J. Geophys. Res., 108(B8), 2390. DOI: 10.1029/2002JB002321

Brodsky, E.E. and Prejean, S.G.: 2005, New constraints on mechanism sof remotely triggered seismicity at Long Valley Caldera. J. Geophys. Res., 110, B04302. DOI: $10.1029 / 2004 J B 003211$

Crank, J.: 1975, The Mathematics of Diffusion. Oxford Sci., Oxford, U.K.

Chadha, R.K., Singh, C. and Shekar, M.: 2008, Transient changes in well-water level in bore wells in western India due to the $2004 \mathrm{Mw} 9.3$ Sumatra earthquake. Bull. Seismol. Soc. Am., 98, 2553-2558. DOI: $10.1785 / 0120080952$

Chen, Y. and Huang, T.F.: 2001, Rock Physics. Beijing University Press, Beijing, China, 9 pp, (in Chinese).

Candela, T., Brodsky, E.E., Marone, C. and Elsworth, D.: 2014, Laboratory evidence for particle mobilization as mechanism for permeability enhancement via dynamic stressing. Earth Planet. Sci. Lett., 392, 279-291. DOI: $10.1016 /$ j.epsl.2014.02.025

Doan, M. L., Brodsky, E. E., Prioul, R. and Signer, C.: 2006, Tidal analysis of borehole pressure-A tutorial. Schlumberger Research report, P35.

Elkhoury, J.E., Brodsky, E.E. and Agnew, D.C.: 2006, Seismic waves increase permeability. Nature, 411, 1135-1138. DOI: 10.1038/nature04798

Elkhoury, J.E., Niemeijer, A., Brodsky, E.E. and Marone, C.: 2011, Laboratory observations of permeability enhancement by fluid pressure oscillation of in-situ fractured rock. J. Geophys. Res., 116, B02311. DOI: $10.1029 / 2010 J B 007759$.

Hill, D.P. et al.: 1993, Seismicity remotely triggered by the magnitude 7.3Landers, California, earthquake. Science, 260, No. 5114, 1617- 1623. DOI: $10.1126 /$ science.260.5114.1617

Hsieh, P.A., Bredehoeft, J.D. and Farr, J.M.: 1987, Determination of aquifer transmissivity from Earth tide analysis. Water. Resour. Res., 23(10), 1824-1832. DOI: 10.1029/WR023i010p01824

Johnston, M.J.S., Hill, D.P., Linde, A.T., Langbein, J. and Bilham, R.: 1995, Transient deformation during triggered seismicity from the 28 June $1992 \mathrm{M}=7.3$ Landers earthquake at Long Valley volcanic caldera, California. Bull. Seismol. Soc. Am., 85, No. 3, 787795.

King, C.-Y., Azuma, S., Igarashi, G., Ohno, M., Saito, H. and Wakita, H.: 1999, Earthquake-related water-level changes at 16 closely clustered wells in Tono, central Japan. J. Geophys. Res., 104, No. B6, 13, 073-13, 082. 
Lin, J. and Stein, R.S.: 2004, Stress triggering in thrust and subduction earthquakes and stress interaction between the southern San Andreas and nearby thrust and strikeslip faults. J. Geophys. Res.,109, No. B02303. DOI: $10.1029 / 2003$ JB002607

Linde, A.T., Sacks, I.S., Johnston, M.J.S., Hill, D.P. and Bilham, R.G.: 1994, Increased pressure from rising bubbles as a mechanism for remotely triggered seismicity. Nature, 371, 408-410. DOI: $10.1038 / 371408 \mathrm{a} 0$

Liu, Y.R. and Tang, H.M.: 1998, Rock Mass Mechanics. Press of China University of Geosciences, Beijing, China, $112 \mathrm{pp}$.

Lu, Y.Z., Li, S.L., Deng, Z.H., Pan, H.W., Che, S. and Li, Z.X.: 2002, Seismology Analysis and Prediction System Based on GIS (Mapsis Software). Chengdu Map Press, Chengdu, China, (in Chinese).

Lai, G.J., Ge, H.K., Xue, L., Brodsky, E.E., Huang, F.Q. and Wang, W.W.: 2013, Tidal response variation and recovery following the Wenchuan earthquake from water level data of multiple wells in the nearfield. Tectonophysics, 610(12), 1-12. DOI: $10.1016 /$ j.tecto.2013.08.039

Manga, M. and Brodsky, E.E.: 2006, Seismic triggering of eruptions in the far field: Volcanoes and geysers. Annu. Rev. Earth Planet. Sci., 34, 263-291. DOI: 10.1146/annurev.earth.34.031405.125125

Manga, M., Beresnev, I., Brodsky, E.E., Elkhoury, J.E., Elsworth, D., Ingebritsen, S., Mays, D.C. and Wang, C.-Y.: 2012, Changes in permeability by transient stresses: Field observations, experiments and mechanisms. Reviews of Geophysics., 50, RG2004. DOI: 10.1029/2011RG000382.

Matsumoto, N.: 1992, Regression-analysis for anomalous changes of groundwater level due to earthquakes. Geophys. Res. Lett., 19, 1193-1196.

Okada, Y.: 1992, Internal deformation due to shear and tensile faults in a half-space. Bull. Seismol. Soc. Am., $82,1018-1040$.

Roberts, P.M.: 2005, Laboratory observations of altered porous fluid flow behavior in Berea sandstone induced by low-frequency dynamic stress stimulation. Acoust. Phys., 51, 140-148. DOI: 10.1134/1.2133962

Roeloffs, E.A.: 1996, Poroelastic techniques in the study of earthquakes-related hydrologic phenomena. Adv. Geophys., 37, 135-195. DOI: $10.1016 / \mathrm{S} 0065-2687(08) 60270-8$

Roeloffs, E.A.: 1998, Persistent water level changes in a well near Parkfield, California, due to local and distant earthquakes. J. Geophys. Res., 103, B1, 869-889. DOI: $10.1029 / 97 \mathrm{JB} 02335$

Rojstaczer, S. and Agnew, D.C., 1989, The influence of formation material properties on the response of water levels in wells to Earth tides and atmospheric loading. J. Geophys. Res., 94(B9), 12403-12411. DOI: $10.1029 / J B 094$ iB09p12403
Sil, S.: 2006, Response of Alaskan wells to near and distant large earthquakes: M.S. thesis, University of Alaska Fairbanks.

Sil, S. and Freymueller, J.T.: 2006, Well water level changes in Fairbanks, Alaska, due to the great Sumatra-Andaman earthquake. Earth Planets Space, 58, 181-184. DOI: 10.1186/BF03353376

Toda, S., Stein, R.S., Richards-Dinger, K. and Bozkurt, S.: 2005, Forecasting the evolution of seismicity in southern California: Animations builton earthquake stress transfer. J. Geophys. Res., 110, B05S16. DOI: $10.1029 / 2004 J B 003415$.

Wang, H.F.: 2000, Theory of linear poroelasticity with application to geomechanics and hydrogeology. Princeton University Press, Princeton, $62 \mathrm{pp}$.

Wang, C.-Y.: 2007, Liquefaction beyond the near field. Seismol. Res. Lett., 78, 512-517. DOI: $10.1785 /$ gssrl.78.5.512

Wang, C.-Y. and Chia, Y.: 2008, Mechanism of water level changes during earthquakes: Near field versus intermediate field. Geophys. Res. Lett., 35, L12402. DOI: 10.1029/2008GL034227

Wang, C.-Y., Chia, Y., Wang, P. L. and Dreger, D.: 2009, Role of $\mathrm{S}$ waves and Love waves in coseismic permeability enhancement. Geophys. Res. Lett., 36, L09404. DOI: 10.1029/2009GL037330

Wang, C.-Y. and Manga, M.: 2010, Earthquakes and Water, Series: Lecture Notes in Earth Sciences. Springer Press, Berlin, 18-24.

Wang, J.L. and Xu, P.W.: 2011, Analysis of geological conditions of geothermal resources in Fuxin city of Fuxin basin. China New Technologies and Products, 20, 31, (in Chinese).

Yan, R., Huang, F.Q. and Chen, Y.: 2007, Application of wavelet decomposition to remove barometric and tidal response in borehole water level. Earthquake Research in China, 23(2), 204-210, (in Chinese).

Yan, R., Woith, H. and Wang, R.J.: 2014, Groundwater level changes induced by the 2011 Tohoku earthquake in China mainland. Geophys. J. Int., 199, 533-548. DOI: $10.1093 /$ gii/ggu196

Zhao, L.F., Xie, X.B., Wang, W.M. and Yao, Z.X.: 2008, Regional seismic characteristics of the 9 October 2006 north Korean nuclear test. Bull. Seismol. Soc. Am., 98, No. 6, 2571-2589. DOI: 10.1785/0120080128 